\title{
In silico and functional characterization of the promoter of a Eucalyptus secondary cell wall associated cellulose synthase gene (EgCesA1)
}

\author{
Nicky Creux ${ }^{1 *}$, Minique De Castro ${ }^{2}$, Martin Ranik ${ }^{3}$, Antanas Spokevicius ${ }^{4}$, Gerd Bossinger ${ }^{4}$, Christine Maritz-Olivier ${ }^{5}$, \\ Zander Myburg ${ }^{1}$
}

From IUFRO Tree Biotechnology Conference 2011: From Genomes to Integration and Delivery

Arraial d'Ajuda, Bahia, Brazil. 26 June - 2 July 2011

\section{Background}

Cellulose is an important biopolymer produced by all plants and is used in a number of different industries, including for pulp and paper production. Cellulose is deposited into the plant cell wall by a large membranebound protein complex, which is composed of different cellulose synthase (CESA) proteins. The cellulose content and pattern of deposition in plant cell walls is highly variable depending on the function of the cell. All plant cells have a thin primary cell wall, but a number of plant cell types, including xylem cells, also deposit a secondary cell wall to give these tissues mechanical strength required to perform their function. Different cellulose synthase (CesA) genes have been shown to be involved in the deposition of primary and secondary walls. In Arabidopsis, three CesA (AtCesA4, 7 and 8) genes have consistently been associated with cells depositing secondary cell walls, while a different set of CesA genes have been shown to function during primary cell wall formation [Reviewed in 1]. These findings have been mirrored by studies of CesA gene orthologs in Populus and Eucalyptus[2-4]. While there have been a number of studies on CesA genes and their functions, much less is known about the regulation of these genes. In a previous study, we investigated the promoters of CesA genes involved in primary and secondary cell wall formation by performing a phylogenetic footprinting analysis to identify cis-elements conserved in the promoters from orthologous Arabidopsis, Populus and Eucalyptus cellulose synthase genes [5]. We identified a

\footnotetext{
* Correspondence: nicky.creux@fabi.up.ac.za

'Department of Genetics, Forestry and Agricultural Biotechnology Institute (FABI), University of Pretoria, South Africa

Full list of author information is available at the end of the article
}

number of putative cis-regulatory elements that may play a role in the regulation of cellulose biosynthesis during primary and secondary cell wall formation. In the current study our aim is to further validate the ciselements identified in the $\operatorname{Ces} A$ gene promoters by investigating their conservation across different Eucalyptus species and to determine the regulatory function of these promoter regions and the proteins which bind to them.

\section{Methods}

A number of different methods are being employed to investigate the regulatory functions associated with the EucalyptusCesA promoters. Firstly, to validate the ciselements previously identified, we cloned and sequenced the promoters of six CesA genes from 13 different Eucalyptus species. The promoter sequences were analysed on the nucleotide diversity level. The cis-elements identified in the previous study were mapped onto the cloned promoter sequences and analysed for conservation in sequence and position. Next, we studied the possible roles of promoter regions harbouring conserved cis-elements in spatio-temporal regulation of Ces $A$ genes. We tested regions of the EucalyptusgrandisCesA1 (EgCesA1) promoter for involvement in spatio-temporal regulation by cloning the full-length $(2 \mathrm{~kb})$ promoter and a series of truncates thereof upstream of the $\beta$-glucuronidase (GUS) reporter gene. These constructs were used to transform Arabidopsis (floral dipping) and Eucalyptus (Induced Somatic Sector Analysis, [6]). The GUS expression patterns were compared to the pattern produced by the $2 \mathrm{~kb} E g C e s A 1$ promoter. Finally, promoter regions identified as functionally active and harbouring conserved elements of interest are being used to screen

c 2011 Creux et al; licensee BioMed Central Ltd. This is an open access article distributed under the terms of the Creative Commons Attribution License (http://creativecommons.org/licenses/by/2.0), which permits unrestricted use, distribution, and reproduction in any medium, provided the original work is properly cited. 
a Eucalyptus immature xylem cDNA expression library for yeast-1-hybrid interactions to identify proteins which interact with these regions.

\section{Results and discussion}

Studying the diversity of CesA promoter sequences and cis-elements in 13 Eucalyptus species provided us with valuable insight into the relative conservation of specific promoters regions and the cis-elements within these regions. We found that the overall nucleotide diversity of the promoter sets varied greatly from promoter to promoter, but we could identify regions in the promoters that were as conserved as coding regions. We found that in many cases these localized decreases in nucleotide diversity corresponded to clusters of conserved ciselements which were identified previously [5]. This was particularly noticeable at the transcriptional start site for most genes and in this region we noticed a repeat element in all of the promoters investigated. Some elements were also shown to be specific to either the primary or secondary cell wall associated promoters. The cis-element information obtained from this study was used to create seven truncates of the EgCesA1 promoter. Using GUS expression analysis in Arabidopsis we identified a number of repression and activation sites within the promoter. We also observed a loss of leaf (vein) expression $800 \mathrm{bp}$ upstream. One of the repeat elements fused to the 5'UTR greatly enhanced overall GUS expression in a non-specific way. In a Eucalyptus background (ISSA), six of the seven truncates showed xylem-specific expression, but the 5'UTR and repeat element fusion showed GUS expression in phloem and xylem. These regions have been used to construct bait vectors for Yeast-1-hybrid screening which is still ongoing.

\section{Conclusion}

In this study we addressed three main objectives, (1) investigate the evolution of the EucalyptusCesA promoters and cis-elements associated with primary and secondary cell wall formation, (2) investigate the expression patterns of truncated versions of the $E g C e s A 1$ promoter using the GUS reporter system and (3) test the EgCesA1 promoter regions affecting gene expression in a yeast1-hybrid assay to identify possible regulators of this gene. We have identified regions in the promoter that were conserved and corresponded to previously identified cis-elements. Using this information we produced seven promoter truncates and discovered several regions and cis-elements in the EgCesA1 promoter which affect GUS expression patterns. These results will aid in understanding and elucidating transcriptional networks regulating xylogenesis in woody genera such as Eucalyptus.

\section{Author details}

${ }^{1}$ Department of Genetics, Forestry and Agricultural Biotechnology Institute (FABI), University of Pretoria, South Africa. ${ }^{2}$ Agricultural Research Council Biotechnology Platform, Onderstepoort, South Africa. ${ }^{3}$ Department of Forest Ecosystems and Society, Oregon State University, USA. ${ }^{4}$ Department of Forest and Ecosystem Science, Melbourne School of Forest and Ecosystem Science, University of Melborne, Australia. ${ }^{5}$ Department of Genetics,

University of Pretoria, South Africa.

Published: 13 September 2011

\section{References}

1. Taylor NG: Cellulose biosynthesis and deposition in higher plants. New Phytol 2008, 178(2):239-252.

2. Samuga A, Joshi CP: A new cellulose synthase gene (PtrCesA2) from aspen xylem is orthologous to Arabidopsis AtCesA7 (irx3) gene associated with secondary cell wall synthesis. Gene 2002, 296(1-2):37-44

3. Ranik M, Creux NM, Myburg AA: Within-tree transcriptome profiling in wood-forming tissues of a fast-growing Eucalyptus tree. Tree Physiol 2006, 26(3):365-375.

4. Kumar M, Thammannagowda S, Bulone V, Chiang V, Han K-H, Joshi CP, Mansfield SD, Mellerowicz E, Sundberg B, Teeri T, et al: An update on the nomenclature for the cellulose synthase genes in Populus. Trends Plant Sci 2009, 14(5):248-254

5. Creux NM, Ranik M, Berger DK, Myburg AA: Comparative analysis of orthologous cellulose synthase promoters from Arabidopsis, Populus and Eucalyptus: evidence of conserved regulatory elements in angiosperms. New Phytol 2008, 179(3):722-737.

6. Van Beveren KS, Spokevicius AV, Tibbits J, Wang Q, Bossinger G: Transformation of cambial tissue in vivo provides an efficient means for induced somatic sector analysis and gene testing in stems of woody plant species. Functional Plant Biol 2006, 33(7):629-638.

doi:10.1186/1753-6561-5-S7-P107

Cite this article as: Creux et al.: In silico and functional characterization of the promoter of a Eucalyptus secondary cell wall associated cellulose synthase gene (EgCesA1). BMC Proceedings 2011 5(Suppl 7):P107.

\section{Submit your next manuscript to BioMed Central and take full advantage of: \\ - Convenient online submission \\ - Thorough peer review \\ - No space constraints or color figure charges \\ - Immediate publication on acceptance \\ - Inclusion in PubMed, CAS, Scopus and Google Scholar \\ - Research which is freely available for redistribution \\ Submit your manuscript at www.biomedcentral.com/submit}

